Original Research Paper

\title{
Effects of Moisture Content on Thermal Properties of Adobe Bricks as a Sustainable Building Material
}

\author{
Suleman Modu Ngaram \\ Department of Physics, Federal University Gashua, Yobe State, Nigeria
}

Article history

Received: 28-01-2020

Revised: 24-03-2020

Accepted: 15-04-2020

Email: ngaramsuleiman@fugashua.edu.ng

\begin{abstract}
The adobe is a widely used traditional material in popular building construction in rural areas of Northeastern, Nigeria and more generally in African countries. In order to increase comfort and energy efficiency of buildings, it is necessary to better consider the thermal properties of the adobe. Adobes at different locations as a function of moisture content have been studied. Thermal conductivity and thermal resistivity were measured by means of a single probe method. Density was estimated by the ratio of mass to volume. The measured values of thermal conductivity and thermal resistivity of adobe soil are varying between 0.191 to $0.428 \mathrm{~W} / \mathrm{m} \mathrm{K}$ and 2.34 to $5.23 \mathrm{mK} / \mathrm{W}$ in the moisture content range 5$20 \%$ wet basis. However, the effect of moisture content increase by increasing the thermal conductivity and decreases the resistivity of soil samples. Regression analysis was carried out which could be used to reasonably estimate the values of the thermal conductivity and resistivity as a function of specified moisture content. For the adobe soils studied, thermal properties increased with increasing soil moisture content.
\end{abstract}

Keywords: Adobe Brick, Thermal Properties, Moisture Content, Building Material

\section{Introduction}

Adobe bricks have been an important component of buildings in Nigeria before the advent of sandcrete blocks. Particularly in the Northeastern part of the country, locally made adobe bricks were the major materials as walling component in a building, (Raheem et al., 2012), walling materials in any building contributes about $25 \%-30 \%$ of the total building cost. The study of temperature distribution in soil profiles requires a solution of the heat transfer equation. This solution depends on the formulation of the boundary condition as well as the soil thermal properties, which are represented by the thermal conductivity and thermal resistivity coefficients (Gnatowski, 2009).

Thermal conductivity is the ratio of heat flux density to temperature gradient in a material. It measures the ability of a substance to conduct heat. Also, thermal resistivity is the ratio of the thermal conductivity of a material (Huang and Liu, 2009). It is a parameter that quantifies the ability of a material to store thermal energy during heat transfer processes. Thermal resistivity is the controlling thermal property during transient conductive heating processes. The literature contains many reports the effect of moisture content, bulk density, temperature, tillage treatments, salt Concentration and organic matter on thermal properties of soils (Edem et al., 2012). Such information assumes greater importance with increasing attention being paid to developing the agricultural and building construction industry in Nigeria. In order to ensure the durability and reduces the shrinkage coefficient with sun-dried adobe bricks, sharp sand is believed to enhance such characteristics. Danso et al. (2015) discussed that earth is the most preferred building material for providing shelter for people especially in less economically developed countries. Construction with adobe is still highly practiced among the communities of developing countries as it is affordable and economical (Hugo and Hubert, 1994). Local people use their experiences and rough estimation in producing bricks manually (Napatsriwattanaprayoon, 2014). Mud is considered inexpensive, broadly available and found environmentally friendly. It consists of stones, sand, silt, clay and organic humus. Adobe construction is unsophisticated technique; easy-to-learn and does not need specialized skills. This construction process relies greatly on human labor and creativity instead of on capital or high technology (Al-Jadeed, 2004). Binici (2007) studied the thermal isolation of fiber reinforced mud bricks as wall materials. Their results showed that the 
fiber reinforced mud brick house results in a temperature of $56.3 \%$ cooler than the concrete brick house in the summer and $41.5 \%$ warmer in the winter. Luisa and Batt (2006) have carried out a detailed study which has shown effect of various factors on the thermal performance of adobe construction. The effect of wall thickness, thermal conductivity and heat capacity has been studied by (Givoni and Katz, 1985). Martin et al. (2010) conducted a field experiment to investigate the thermal behavior of existing housing in Spain. They compared, stone, adobe and wooden houses (modern). The results demonstrate better indoor conditions in the traditional houses. In summer, thermal comfort was achieved with no energy supply inside traditional houses but not inside the modern ones. In winter, the indoor environment was more stable inside the traditional houses; however no house was able to provide thermal comfort.

Therefore the objective of this study is to determine apparent thermal conductivity and thermal resistivity values for adobe soil as a function of moisture content as sustainable bricks for buildings construction in Gashua, Yobe State, Nigeria.

\section{Adobe Sustainable Brick Survey}

Energy reservations: Presently housing consists of, approximately, $40 \%$ of total energy demand in the European Union (EU) (Viviancos et al., 2009; Martin et al., 2010). Therefore, reducing energy consumption in heating and cooling of buildings is an issue of increasing interest, with multiple organizations conducting research into this area. EU Energy Performance of Buildings Directive (EPBD) was implemented in the legislation of Member States on January 4, 2006. This directive is an important step for the EU to decrease energy consumption (Viviancos et al., 2009).

Sustainable development includes socio-economic and environmental targets and concerns all sectors of human activity. The major reasons for green building are to reduce energy consumption, greenhouse gas emission, water use and waste production versus traditional building. Earthen housing appears to meet the requirements of green construction (Shukla et al., 2009) calculated the energy for construction and maintenance of an adobe house. Adobe is able to absorb heat during the day keeping the house cool and then release this stored heat at night, warming the interior of the house. This behavior is due to the high specific heat capacity of adobe which is an important factor that allows this material to reduce the thermal gradient of earthen houses (Parra-Saldivar and Batty, 2006). On the other hand, the ability of adobe to conduct heat is highly dependent on its moisture content with a strong relationship between water content and heat conduction (Rees et al., 2001). Actual adobe constructions have wet-dry cycles due to rain and relative humidity that cause changes in its thermal behavior. The presence or absence of internal walls is another important factor that modifies room temperature and determines the thermal behavior of the internal space of the building. In terms of temperature attenuation the thickest internal wall shows the greatest effect for most climatic regions during the year (Parra-Saldivar and Batty, 2006). It is also mentioned that fiber reinforced mud brick houses have been found to be superior to concrete brick houses in reducing large fluctuations of indoor temperatures during the summer and winter (Martin et al., 2010).

Demir (2008) showed that sawdust, tobacco residues and grass can be used to improve the thermal and mechanical properties of adobe bricks. The insulation capacity of brick increases with the increasing porosity of the body clay. The organic residue additions were found to be effective for pore-forming in the clay body and the clay maintained acceptable mechanical properties.

\section{Theory}

The single probe method is based on a solution of the heat conduction equation for a line heat source in a homogenous and isotropic medium at a uniform initial temperature. The equation for radial heat conduction can be represented as (Fontana et al., 2001):

$\frac{\partial T}{\partial t}=\rho\left(\frac{\partial^{2} T}{\partial r^{2}}+\frac{1}{2 r} \frac{\partial T}{\partial t}\right)$

where, $T$ is temperature $\left({ }^{\circ} \mathrm{C}\right), t$ is time $(s), \rho$ is thermal resistivity $\left({ }^{\circ} \mathrm{C} / \mathrm{W}\right)$ and $r$ is radial distance $(m)$. The solution to Equation (1) is (Aghbashlo et al., 2008; Opoku et al., 2006):

$T-T_{0}\left(\frac{4 \pi K}{Q}\right) e\left(\frac{-i r^{2}}{4 \rho t}\right)$

where, $Q$ is the heat per unit length per unit time $(\mathrm{W} / \mathrm{m}), K$ is the thermal conductivity $\left(\mathrm{W} / \mathrm{m}^{\circ} \mathrm{C}\right), \mathrm{T}_{\mathrm{O}}$ is initial temperature of soil $\left({ }^{\circ} \mathrm{C}\right)$ and e is an exponential integral function.

The heat input of line heat source can be calculated as:

$Q=I^{2} R$

where, $\mathrm{I}$ is the current (A) and $R$ is the resistance of the heat wire per unit length $(\Omega / \mathrm{m})$. Thus, the Equation (2) can be expressed as (Ekwue et al., 2006; Fontana et al., 2001):

$T-T_{0}=\left(\frac{4 \pi K}{Q}\right)\left(\ln (t)-\alpha-\ln \left(\frac{r^{2}}{4 \rho}\right)\right)$

where, $\alpha$ is Euler's constant [0.5772], Equation (4) means that the gradient of a plot of $(\Delta \mathrm{T})$ versus natural 
logarithm of $[\ln (t)]$ is equal to $S=\frac{Q}{4 n k}$. Hence the thermal conductivity can then be calculated as:

$K=\frac{Q}{4 \pi S}$

And the thermal resistivity is given by taken the reciprocal of thermal conductivity:

$\rho=\frac{1}{K}(m K / W)$

\section{Materials and Methods}

\section{Single Probe Method}

The line heat source probe method used for the determination of thermal properties simultaneously (Fig. 1a). The probe, which is $90 \mathrm{~mm}$ long and $6 \mathrm{~mm}$ in diameter, consists of a heater wire of resistance 30.4 $\Omega / \mathrm{m}$ (Fig. 1b). The space between the heating element and the stainless steel tube is filled with thermal epoxy, which provides excellent thermal conduction and acts as an electrically insulated material. The temperature of the probe can be determined with the help of a Type-K thermocouple, which is attached to its surface. The sample holder has a PTF cylinder with an inner diameter of $50 \mathrm{~mm}$, a length of $150 \mathrm{~mm}$ with a movable piston (for compression of soil samples) to examine the effects of compaction on thermal properties. To determine the bulk thermal properties of soil, samples at the desired moisture content and temperature were tightly packed inside the sample holder and compaction was done by movable piston. The tightly filled sample was weighed by digital balance (A\&D GF600, Japan) and recorded. The bulk density of the sample in the sample holder was calculated by the ratio of mass to volume. Following this, the probe was inserted through the center of the sample. Then the sample holder was placed in a water bath in order to heat it to the desired temperature. As soon as a constant temperature of the thermocouples was reached, a constant DC voltage was applied from the power supplier, resulting in a constant electric current through the heating wire. A digital multi-meter was used to monitor the current. The thermocouple temperatures were recorded by the data logger every second for $3 \mathrm{~min}$. After one replication, the probe was cooled to the initial temperature before the next replication began.

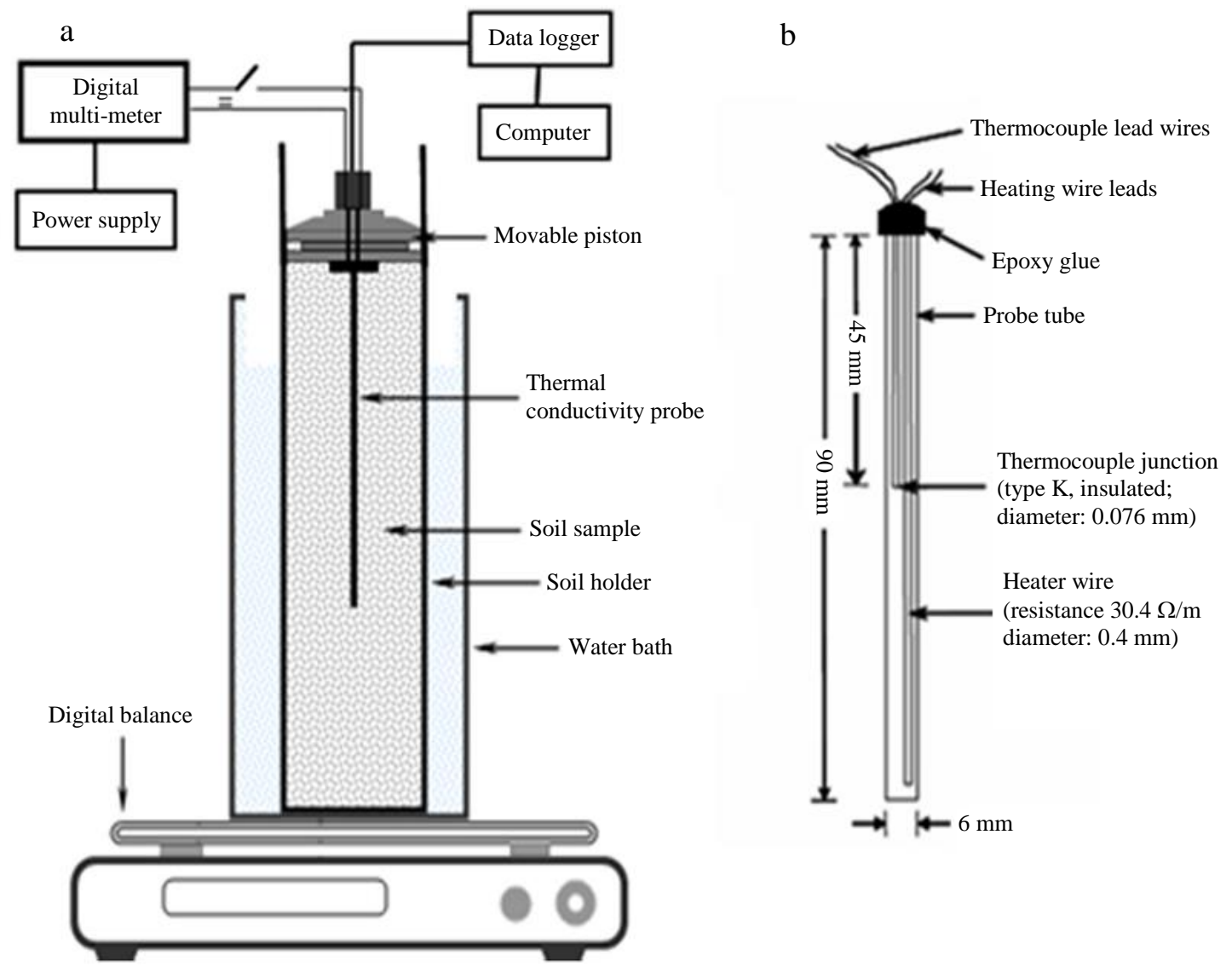

Fig. 1: Schematic diagram of the experimental set-up (a) and thermal conductivity probe (b) (Amrollah, 2014) 


\section{Soil Sample Preparation}

The clay/sand soil representing major building soils in Gashua, Yobe State was selected. The soil samples were collected horizontally from the top layer (5 to 15 $\mathrm{cm}$ ) of soil profile located at Katuzu and Sabon gari in Gashua, Nigeria. Soil particle size distribution was determined using the hydrometer method. Soil had an initial moisture content of $20.8 \pm 0.5 \%$ wet basis which was determined by using a standard oven method at $105^{\circ} \mathrm{C}$ for $24 \mathrm{~h}$ (Ekwue et al., 2011). The moist soil samples was dried in a hot air oven at $70^{\circ} \mathrm{C}$ to get the desired moisture content of 20\%, $15 \%, 10 \%$ and $5 \%$ wet basis. Each dried soil sample was kept in a plastic box which was sealed by plastic film to prevent moisture loss. Then it was refrigerated at $7^{\circ} \mathrm{C}$ for at least $24 \mathrm{~h}$ to allow moisture in the samples to equilibrate before analysis. Finally, moisture content of the sample was checked again before use to ensure it was at the correct level.

\section{Statistical Analysis}

The experiments are carried out at four replications and the mean values of data are reported with standard deviation. An analysis of variance was conducted at 0.01 confidence level to examine the effect of moisture content on the thermal conductivity and resistivity. The statistical evaluation was performed by using SPSS software Ver.2.0. Also, the coefficient of determination $\left(R^{2}\right)$ and Standard Error of the Residuals (SER) were calculated to evaluate the fitting of mathematical relationships to experimental data.

\section{Results and Discussion}

The measured values of thermal conductivity and resistivity with various moisture contents of clay-sandy soil are presented in Table 1. It was found that thermal conductivity of soil samples increased with an increase in moisture content $(P \leq 0.03)$, which was in agreement with some previous researchers who studied thermal conductivity of other soils (Evett et al., 2012; Ekwue et al., 2011). This may be due to the fact that the thermal conductivity of water ranges from 0.6106 to 0.6372 $\mathrm{W} / \mathrm{m} \mathrm{K}$ at temperatures of $26.5-45^{\circ} \mathrm{C}$ (Mahmoodi and
Kianmehr, 2008) which is much higher than that of air filled in pores following reduction in moisture. Regarding the effect of the pore of air is a poor heat conductor and has very low thermal conductivity, about $0.0272 \mathrm{~W} / \mathrm{m} \mathrm{K}$ at about $38^{\circ} \mathrm{C}$, as compared to the solid particles of soil sample and moisture (Amrollah, 2014). The measured values of the thermal conductivity of the clay-sandy soil are varying between 0.191 to approximately $0.428(\mathrm{~W} / \mathrm{mK})$ in the moisture content range $5-20 \%$ wet basis for Gashua, Yobe State. Thermal conductivity value reported here lie within the range $0.365-0.791(\mathrm{~W} / \mathrm{mK})$ for clay-loam soil as given by (Amrollah, 2014). Investigations of (Ekwue et al., 2006) showed that the thermal conductivity of compacted Trinidadian soils increased from 0.4 to 2 $\mathrm{W} / \mathrm{mK}$ in the moisture range of $15-50 \%$ wet basis. AbuHamdeh and Reeder (2000) research works showed that the thermal conductivity of the Jordanian clay loam and loam soils increased linearly from 0.3 to $0.8 \mathrm{~W} / \mathrm{m} \mathrm{K}$ with moisture increase in the range of $9-18 \%$ wet basis. (Anandakumar et al., 2001) found that the thermal conductivity of sandy-clay soil increased from 0.518 to $2.148 \mathrm{~W} / \mathrm{m} \mathrm{K}$ with increase in moisture content and temperature. Abu-Hamdeh and Reeder (2000) investigations showed that the thermal conductivity increased from 0.58 to $1.94 \mathrm{~W} / \mathrm{m} \mathrm{K}$ for sand, 0.19 to $1.12 \mathrm{~W} / \mathrm{m} \mathrm{K}$ for sandy loam, 0.29 to $0.76 \mathrm{~W} / \mathrm{m} \mathrm{K}$ for loam and 0.36 to $0.69 \mathrm{~W} / \mathrm{m} \mathrm{K}$ for clay loam soil at densities from 1230 to $1590 \mathrm{~kg} / \mathrm{m}^{3}$ and moisture contents from 1.4 to $21.2 \%$ wet basis. Variation of thermal resistivity clay-sandy soil samples as a function of moisture content is shown in Fig. 2. The thermal resistivity values of soil samples were varied in the range of 2.33-5.23 (mK/W) (Fig. 3). The increased thermal conductivity with increasing moisture content might be due to higher thermal conductivity of water compared to the dry material of sample associated with air-filled pores. Initially, thermal resistivity decreases with an increase in moisture content for soil samples. Also, to evaluate the individual effect of independent variable on the thermal conductivity, Analysis of Variance (ANOVA) was also carried out as shown in Table 2.

Table 1: Result of experimental values.

\begin{tabular}{llll}
\hline S/No. & Thermal conductivity $\mathrm{K}\left(\mathrm{Wm}^{-1} \mathrm{k}^{-1}\right)$ & Moisture content $(\%)$ & Resistivity $\rho(\mathrm{mK} / \mathrm{W})$ \\
\hline 1 & 0.1911 & 5 & 5.233 \\
2 & 0.2569 & 10 & 3.893 \\
3 & 0.3212 & 15 & 2.335 \\
4 & 0.4282 & 20 & 3.893 \\
\hline
\end{tabular}

Table 2: Analysis of Variance (ANOVA) for effect of moisture content on thermal conductivity and resistivity of adobe bricks

\begin{tabular}{llllll}
\hline Model & Sum of squares & df & Mean square & F & Sig. \\
\hline 1 Regression & 124.999 & 2 & 62.499 & 45057.541 \\
Residual & 0.001 & 1 & 0.001 & $0.003^{\text {b }}$ \\
Total & 125.000 & 3 & & \\
\hline
\end{tabular}

a. Dependent Variable: Moisture content

b. Predictors: (Constant), Thermal conductivity, Thermal resistivity 


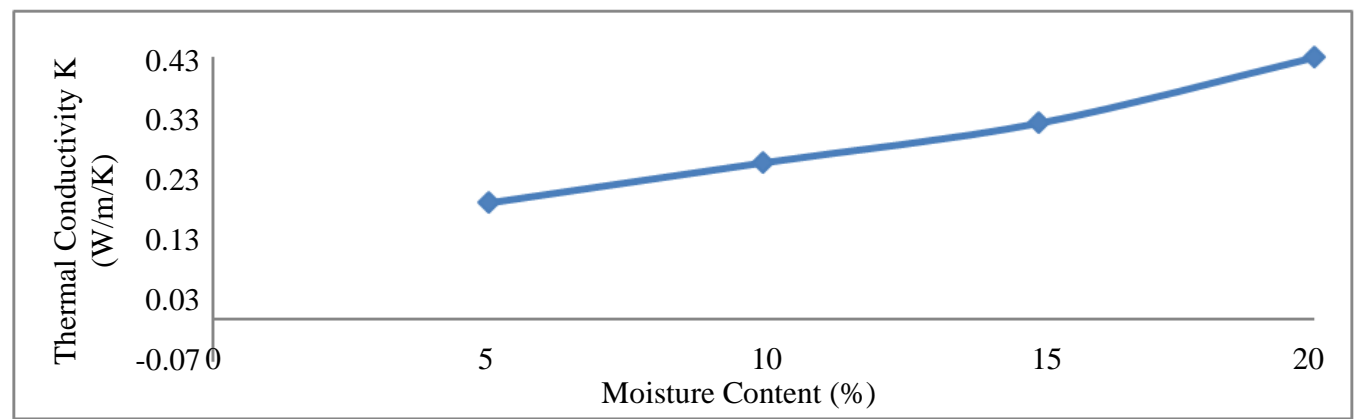

Fig. 2: Effect of Moisture content on thermal conductivity

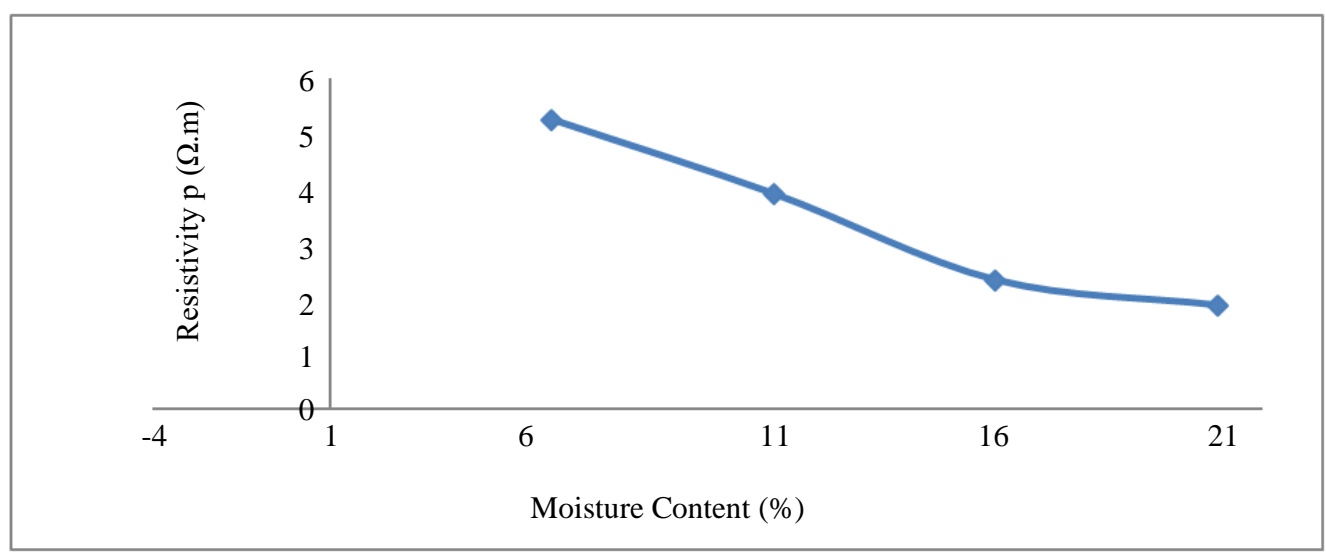

Fig. 3: Effect of Moisture content on thermal resistivity

\section{Conclusion}

Results of this investigation clearly showed significant variation in thermal conductivity of adobequartz soil as sustainable building material with changing moisture content. The thermal conductivity increased from 0.191 to $0.428 \mathrm{~W} / \mathrm{m} \mathrm{K}$ and the thermal resistivity decreases from 5.233 to $2.34 \mathrm{mk} / \mathrm{W}$. The effect of moisture content on increasing the thermal conductivity of clay-sand soil made it one of the factors affecting the thermal properties of soil.

\section{Acknowledgement}

The authors wish to thank the Federal University Gashua for funding this research work through the Tertiary Education Trust Fund (Tetfund) Institutional Based Research (IBR) grant, 2019.

\section{Ethics}

This article is original and contains unpublished material. The corresponding author confirms that all of the other authors have read and approved the manuscript and no ethical issues involved.

\section{References}

Abu-Hamdeh, N.H. and R.C. Reeder, 2000. Soil thermal conductivity: Effects of density, moisture, salt concentration and organic matter. Soil Sci. Society Am. J., 64: 1285-1290.

DOI: $10.2136 /$ sssaj2000.6441285x

Aghbashlo, M., M.H. Kianmehr and S.R. Hassan-Beygi, 2008. Specific heat and thermal conductivity of berberis fruit (Berberis vulgaris). Am. J. Agric. Biol. Sci., 3: 330-336.

DOI: 10.3844/ajabssp.2008.330.336

Al-Jadeed, M.A.A., 2004. Mud architecture in Arab and western countries. J. Al-Madinah Al- Munawwarah Res. Studies Center, 8: 105-138.

Amrollah, G., 2014. Clay-Loam soil thermal properties survey. Int. J. Adav. Applied Sci., 1: 31-36.

Anandakumar, A., R. Venkatesan and V.P. Thara, 2001. Soil thermal properties at Kalpakkam in coastal south India. Indian Acad. Sci., 110: 239-245. DOI: $10.1007 / \mathrm{BF} 02702239$

Binici, H., 2007. Thermal isolation and mechanical properties of fibre reinforced mud bricks as wall materials. Constr. Build. Mater., 21: 901-906. 
Demir, I., 2008. Effect of organic residues addition on the technological properties of clay bricks. Waste Manage., 28: 622-627. DOI: 10.1016/j.wasman.2007.03.019

Edem, I.D., P.M. Eko and N.M. John, 2012. Effect of animal droppings on thermal properties of dispersed porous system. Trends Soil Sci. Plant Nutrit. J., 3: 1318-1318.

Ekwue, E.I., R.J. Stone and D. Bhagwat, 2006. Thermal conductivity of some compacted Trinidadian soils as affected by peat content. Biosyst. Eng., 94: 461-469. DOI: 10.1016/j.biosystemseng.2006.03.002

Ekwue, E.I., R.J. Stone and D. Bhagwat, 2011. Thermal conductivities of some common soils in Trinidad. The West Indian J. Eng., 33: 4-11.

Evett, S.R., A. Agam, W.P. Kustas, P.D. Colaizzi and R.C. Schwartz, 2012. Soil profile method for soil thermal diffusivity, conductivity and heat flux: Comparison to soil heat flux plates. Adv. Water Res., 50: 41-54.

DOI: 10.1016/j.advwatres.2012.04.012

Fontana, A.J., B. Wacker, C.S. Campbell and G.S. Campbell, 2001. Simultaneous thermal conductivity, thermal resistivity and thermal diffusivity measurement of selected foods and soils. Am. Society Agric. Eng.

Givoni, B. and L. Katz, 1985. Earth temperatures and underground buildings. Energy Buil., 8: 15-25.

DOI: 10.1016/0378-7788(85)90011-8

Gnatowski, T., 2009. Analysis of thermal diffusivity data determined for selected organic topsoil layer. Annals Warsaw Univ. Life Sci. SGGW, 41: 95:107. DOI: 10.2478/v10060-008-0053-y

Huang, L. and L.S. Liu, 2009. Simultaneous determination of thermal conductivity and thermal diffusivity of food and agricultural materials using a transient plane-source method. J. Food Eng., 95: 179-185. DOI: 10.1016/j.jfoodeng.2009.04.024

Hugo, H. and G. Hubert, 1994. Earth Construction; A Comprehensive Guide. 1st Edn., London UK, pp: 362.

Luisa, P.M. and W. Batty, 2006. Thermal behaviour of adobe constructions. Buil. Environ., 41: 1892-1904. DOI: 10.1016/j.buildenv.2005.07.021
Mahmoodi, M. and M.H. Kianmehr, 2008. Determination and comparison of thermal conductivity of Iranian pomegranate varieties. Proceedings of the 18th Natinal Congerss on Food Technology, Oct. 15-16, Mashhad, Iran.

Martin, S., F.R. Mazarron and I. Canas, 2010. Study of thermal environment inside rural houses of Napolos (Spain). The advantage of reuse building of high thermal inertia. Construct. Build. Mater., 24: 666-676. DOI: 10.1016/j.conbuildmat.2009.11.002

Napatsriwattanaprayoon, 2014. Engineering properties of adobe brick for earth structures IJERD. Int. J. Environ. Rural Dev., 5: 41-6.

Opoku, A., A.G. Tabli, B. Crerar and M.D. Shaw, 2006. The thermal conductivity and thermal diffusivity of timothy hay. Canadian Bioysyt. Eng., 48: 1-7.

Parra-Saldivar, M.L. and W. Batty, 2006. Thermal behavior of adobe constructions. Build. Environ., 41: 1892-1904. DOI: 10.1016/j.buildenv.2005.07.021

Raheem, A.A., O.O Falola and K.J. Adeyeye, 2012. Production and testing of lateritic interlocking blocks. J. Construct. Dev. Countries, 17: 35-50.

Rees, S.W., Z. Zhou and H.R. Thomas, 2001. The influence of soil moisture content variations on heat losses from earth-contact structures: An initial assessment. Build. Environ., 36: 157-165. DOI: 10.1016/S0360-1323(99)00063-3

Shukla, A., G.N. Tiwari and M.S. Sodha, 2009. Embodied energy analysis of adobe house. Renew. Ener., 34: 755-761.

Viviancos, J.L., J. Soto, I. Perez, J.V. Ros-Li and R. Martininez-Manez, 2009. A new model base on experimental results for the thermal characterization of bricks. Build. Environ., 44: 1047-1052.

Danso, H., D.B. Martinson, M. Ali and J.B. Williams, 2015. Physical, mechanical and durability properties of soil building blocks reinforced with natural fibres. Constr. Build. Mater., 101: 797-809.

DOI: 10.1016/j.conbuildmat.2015.10.069 